\title{
УПРАВЛЕНИЕ ГОСУДАРСТВЕННОЙ СОБСТВЕННОСТЬЮ КАК ФАКТОР ВЛИЯНИЯ НА ИННОВАЦИОННОЕ РАЗВИТИЕ ЭКОНОМИКИ РОССИИ
}

\author{
(c) 2019 Звягинцев Петр Семенович \\ кандидат экономических наук, ведущий научный сотрудник \\ Институт экономики Российской академии наук, Россия, Москва \\ E-mail: petrz@bk.ru
}

В статье рассматривается роль инноваций как важнейшего фактора развития социальноэкономического прогресса. Проведен анализ содержания государственной Программы «Управление федеральным имуществом» и вносимых в нее изменений. Приведен уровень инновационной активности организаций по формам собственности. Обосновывается вывод о необходимости сохранения государственных предприятий, с помощью которых осуществлять масштабные инновационные программы.

Ключевые слова: инновации, управление, государственная программа, государственная и частная собственность, инновационная активность.

В настоящее время в обеспечении устойчивого развития экономики первостепенная роль принадлежит инновациям, способным обеспечить непрерывное обновление технической и технологической базы производства, освоение и выпуск новой конкурентоспособной продукции.

Инновации влияют на структуру общественного производства, видоизменяют экономическую организацию общества, стабилизируют социальную ситуацию в стране и, таким образом, становятся стратегическим фактором экономического роста.

Поэтому важнейшей стратегической целью государственной политики является переход российской экономики на инновационный путь развития.

В Стратегии инновационного развития Российской Федерации на период до 2020 года написано: «Россия ставит перед собой амбициозные, но достижимые цели долгосрочного развития, заключающиеся в обеспечении высокого уровня благосостояния населения и закреплении геополитической роли страны как одного из лидеров, определяющих мировую политическую повестку дня. Единственным возможным способом достижения этих целей является переход экономики на инновационную социально ориентированную модель развития» [5].

Однако, в Российской Федерации в 2017 году доля инновационно активных организаций составила всего лишь 8,5\% [12]. Удельный вес инновационных товаров, работ, услуг в общем объеме отгруженных товаров, выполненных работ, услуг в 2018 году составил - 6,5\% и 70,7\% по сравнению с 2013 годом (табл. 1).

Доля продукции высокотехнологичных и наукоемких отраслей в валовом внутреннем продукте Российской Федерации в 2018 году составила $21,1 \%$ и уменьшилась на $0,4 \%$ по сравнению с 2014 годом, удельный вес затрат на технологические инновации в общем объеме отгруженных товаров, выполненных работ, услуг Российской Федерации в 2018 году составил 2,1\% и сократился по сравнению 2014 годом на 0,8\%, внутренние затраты на исследования и разработки составили в 2018 году 1\% от валового внутреннего продукта в целом по Российской Федерации и уменьшились на 0,07\% по сравнению с 2014 годом [13].

Следовательно, происходит не рост затрат

Таблица 1. Удельный вес инновационных товаров, работ, услуг в общем объеме отгруженных товаров, выполненных работ, услуг, РФ,\%

\begin{tabular}{|c|c|c|c|c|c|c|}
\hline & \multicolumn{7}{|c|}{ Годы } \\
\cline { 2 - 8 } & $\mathbf{2 0 1 3}$ & $\mathbf{2 0 1 4}$ & $\mathbf{2 0 1 5}$ & $\mathbf{2 0 1 6}$ & $\mathbf{2 0 1 7}$ & $\mathbf{2 0 1 8}$ \\
\hline \multirow{2}{*}{ Российская Федерация } & 9,2 & 8,7 & 8,4 & 8,5 & 7,2 & 6,5 \\
\cline { 2 - 8 } & 100,0 & 94,6 & 91,3 & 92,4 & 78,3 & 70,7 \\
\hline
\end{tabular}

Источник: Федеральная служба государственной статистики, gks.ru [13]. 
на исследования и разработки, а их уменьшение, что вызвало уменьшение инновационной активности организаций. Поэтому представляется чрезвычайно важным переход всех промышленных предприятий России на инновационный путь развития и ростом затрат на исследования и разработки.

Источником финансирования новых технологий являются государственные инвестиционные программы, которые становятся средством решения стратегических задач развития инновационной экономики. Государственные программы являются одним из важнейших инструментов реализации структурной, научно-технической и инновационной политики государства.

Государственные программы направления «Инновационное развитие и модернизация экономики» являются основным источником создания новой инновационной продукции. Данное направление государственных программ финансирует работы, направленные на создание и выпуск новой инновационной продукции, на обновление промышленности на новой технологической основе.

Однако небольшое бюджетное финансирование данных программ и многие недостатки, возникающие при их разработке и реализации, не дают российской экономике значимых позитивных результатов [7].

Анализ состояния инновационной деятельности российских предприятий показывает зависимость инновационной активности предприятий от их формы собственности и системы ее управления.

Управление имуществом осуществляется постановлением Правительства Российской Федерации от 9 сентября 1999 года № 1024 «О Концепции управления государственным имуществом и приватизации в Российской Федерации» [1].

Правительство Российской Федерации своим распоряжением от16.02.2013 № 191-р утвердило государственную программу «Управление федеральным имуществом». 15 апреля 2014 г. Правительство РФ своим постановлением за № 327 утвердило государственную программу РФ «Управление федеральным имуществом», которая была существенно изменена [2].

Основные цели Программы:

1. Создание условий для эффективного управления федеральным имуществом, необхо- димым для выполнения государственных функций органами государственной власти Российской Федерации, и отчуждения федерального имущества, востребованного в коммерческом обороте.

2. Совершенствование системы государственного материального резерва, повышение ее роли в позитивных процессах, происходящих в экономике и политике Российской Федерации и направленных на укрепление экономической независимости и национальной безопасности государства.

Постановлением Правительства РФ от 31 марта 2017 г. № 381-12 были внесены изменения в государственную программу Российской Федерации «Управление федеральным имуществом»: цели и задачи; целевые индикаторы и показатели; сроки реализации Программы; объемы бюджетных ассигнований и ожидаемые результаты [3].

Так, целью в измененной Программе теперь является «Совершенствование механизмов управления и приватизации федерального имущества».

Правительство РФ утверждает (третье) Постановление 30 марта 2018 г. № 367-14 «О внесении изменений в государственную программу Российской Федерации «Управление федеральным имуществом» [4].

В Программе увеличены сроки ее реализации с 2019 года до 2020 года, а также изменены ожидаемые результаты реализации Программы и объемы бюджетных ассигнований. Результаты реализации Программы записаны следующим образом: «Утвержден к 2020 году прогнозный план приватизации федерального имущества и основные направления приватизации федерального имущества на 2020-2022 годы».

Сокращение количества организаций с государственным участием также увеличивается в 2019 году с $24 \%$ до $29,5 \%$ в 2020 году, а имущества государственной казны Российской Федерации за этот период - с $10 \%$ до 10,5\%.

За 8 лет (2013-2020 гг.) реализации Программы количество организаций с государственным участием в 2020 году уменьшится до $42,23 \%$ по отношению к 2012 году, т.е. сократится в 2,37 раза, а имущество государственной казны Российской Федерации соответственно уменьшится до $21,9 \%$, т.е. сократиться в 4,57 раза [8].

По данным Росстата на конец 2017 г., в государственной собственности находится 2,2\% 
предприятий, в собственности общественных и религиозных организаций $-3,1 \%$, в смешанной собственности $-4,1 \%$, в муниципальной $-4,3 \%$, а в частной собственности - 86,3\% [11].

За семнадцать лет (2000-2017 гг.) количество предприятий с частной собственностью увеличилось на $36,24 \%$, а с государственной собственностью сократилось на 46,27\%. Собственности у общественных и религиозных организаций больше, чем предприятий с государственной собственностью на $36,2 \%$.

Программа «Управление федеральным имуществом» продлена до 2020 года, а, следовательно, будет и дальнейшее сокращение организаций с государственным участием и имущества государственной казны. Однако авторы Центра стратегических разработок предлагают дальнейшее проведение сокращения государственного сектора вплоть до 2035 года [14].

С 2019 года создание государственных и муниципальных унитарных предприятий будет запрещено. Ликвидация ГУП и МУП - это очередной шаг по снижению роли государства в экономике страны [9].

Экономическая теория показывает, что для эффективности предприятий важнее не форма собственности, а уровень развития конкуренции и структура рынка. В некоторых случаях приватизация предприятий общественного сектора и естественных монополистов может нанести вред потребителям. Подчас она приводит к сворачиванию инновационных программ. В тоже время, если государству удается превратить госкомпании в институты развития, они могут использовать свой особый статус, в т.ч. правительственную финансовую поддержку, для ускорения ломки консервативных структур и обеспечения более благоприятных условий для развития высокотехнологических отраслей.

В России частники не только «эффективно» уходят в оффшоры и от налогов, они ещё и почти ничего не вкладывают в развитие предприятий. Так, степень износа основных фондов конец 2017 г. превысила этот показатель 1990 г. и, по данным Росстата, составила 48,1\% [10]. Это критический уровень, не говоря уже о моральном износе средств производства. В то же время степень износа основных средств производства в США и в странах Западной Европы составляет не более $20 \%$ [15].

Благодаря госсектору многим странам удается осуществить масштабные научно-техни- ческие программы и сгладить региональные проблемы развития территорий. В данном контексте он выступает в качестве инструмента проведения структурной и научно-технической политики. Поэтому госсектор никак не может квалифицироваться как однозначно негативное явление.

Анализ числа организаций и разработанных и используемых нанотехнологий в 2017 году в Российской Федерации показывает, что число организаций с государственной собственностью, разрабатывавших нанотехнологии, составило 71 единицу, а с частной собственностью -28 единиц. Число разработанных нанотехнологий организациями с государственной собственностью за 2017 год составило 242 единицы, а с частной собственностью - 137 единиц. Число используемых нанотехнологий организациями с государственной собственностью за 2017 год составило 242 единицы, а с частной собственностью -137 единиц (табл. 2).

Следовательно, несмотря на незначительное количество оставшихся у государства предприятий $(2,2 \%)$, число организаций с государственной собственностью, разрабатывавших нанотехнологии, и число разработанных нанотехнологий в 2017 году в Российской Федерации больше числа организаций с частной собственностью и количества разработанных нанотехнологий. Число используемых нанотехнологий организациями с государственной собственностью за 2017 год составило 435 единиц, а число организаций с частной собственностью 428 единиц.

Инновационная активность оставшихся у государства организаций составила 9,7\% в 2017 году в общем числе обследованных организаций, а частных - 9,1\% (см. табл. 3) [6]. Аналогичная ситуация и по технологическим инновациям: соответственно 8,8\% и 7,9\% и процессным инновациям: соответственно 5,5\% и 4,2\%. Наибольший уровень инновационной активности осуществляют государственные корпорации: соответственно 32,0\%, 30,2\% и 16,0\%. Второе место по уровню инновационной активности занимает совместная федеральная и иностранная собственность: $26,6 \%, 25,2 \%$ и $20,1 \%$.

Следовательно, государственные предприятия и корпорации более активно

осуществляют инновационную деятельность, внедряют технологические и процессные инновации по сравнению с частными и другими организациями. 
Таблица 2. Число организаций и число разработанных и используемых нанотехнологий в 2017 году, Российская Федерация (единиц)

\begin{tabular}{|c|c|c|c|c|c|c|}
\hline & & \multicolumn{2}{|c|}{ Число организаций } & \multirow[b]{2}{*}{$\begin{array}{c}\text { Число } \\
\text { разрабо- } \\
\text { танных } \\
\text { нанотех- } \\
\text { нологий }\end{array}$} & \multicolumn{2}{|c|}{$\begin{array}{l}\text { Число используемых } \\
\text { нанотехнологий }\end{array}$} \\
\hline & & $\begin{array}{c}\text { разраба- } \\
\text { тывавших } \\
\text { нанотех- } \\
\text { нологии }\end{array}$ & $\begin{array}{c}\text { исполь- } \\
\text { зовавших } \\
\text { нанотех- } \\
\text { нологии }\end{array}$ & & Всего & $\begin{array}{c}\text { из них } \\
\text { разрабо- } \\
\text { танные в } \\
\text { отчиты- } \\
\text { вающейся } \\
\text { организа- } \\
\text { ции }\end{array}$ \\
\hline 1 & 2 & 3 & 4 & 5 & 6 & 7 \\
\hline 2 & Всего (по всем формам собственности) & 117 & 267 & 446 & 1144 & 528 \\
\hline 3 & Российская собственность & 110 & 242 & 396 & 1036 & 508 \\
\hline 4 & Государственная собственность & 71 & 91 & 242 & 435 & 298 \\
\hline 5 & Федеральная собственность & 69 & 88 & 240 & 415 & 297 \\
\hline 6 & $\begin{array}{l}\text { Собственность субъектов Российской } \\
\text { Федерации }\end{array}$ & 2 & 3 & 2 & 20 & 1 \\
\hline 7 & Муниципальная собственность & & 11 & & 34 & 6 \\
\hline 8 & Частная собственность & 28 & 103 & 137 & 428 & 150 \\
\hline 9 & Смешанная российская собственность & 9 & 29 & 14 & 115 & 32 \\
\hline 10 & Иностранная собственность & 1 & 14 & 29 & 56 & 1 \\
\hline 11 & $\begin{array}{l}\text { Собственность иностранных юридиче- } \\
\text { ских лиц }\end{array}$ & 1 & 14 & 29 & 56 & 1 \\
\hline 12 & $\begin{array}{l}\text { Совместная Российская и иностранная } \\
\text { собственность }\end{array}$ & 6 & 11 & 21 & 52 & 19 \\
\hline 13 & $\begin{array}{l}\text { Совместная федеральная и иностранная } \\
\text { собственность }\end{array}$ & & 1 & & 1 & \\
\hline 14 & $\begin{array}{l}\text { Совместная частная и иностранная соб- } \\
\text { ственность }\end{array}$ & 6 & 10 & 21 & 51 & 19 \\
\hline 15 & $\begin{array}{l}\text { Смешанная Российская собственность с } \\
\text { долей государственной собственности }\end{array}$ & 7 & 24 & 12 & 95 & 21 \\
\hline 16 & $\begin{array}{l}\text { Смешанная российская собственность с } \\
\text { долей федеральной собственности }\end{array}$ & 4 & 14 & 9 & 54 & 17 \\
\hline 17 & $\begin{array}{l}\text { Смешанная российская собственность с } \\
\text { долей собственности субъектов Россий- } \\
\text { ской Федерации }\end{array}$ & 2 & 9 & 2 & 39 & 3 \\
\hline 18 & $\begin{array}{l}\text { Смешанная российская собственность } \\
\text { с долями федеральной собственности } \\
\text { и собственности субъектов Российской } \\
\text { Федерации }\end{array}$ & 1 & 1 & 1 & 2 & 1 \\
\hline 19 & $\begin{array}{l}\text { Иная смешанная российская собствен- } \\
\text { ность }\end{array}$ & 2 & 5 & 2 & 20 & 11 \\
\hline 23 & $\begin{array}{l}\text { Собственность государственных корпо- } \\
\text { раций }\end{array}$ & 2 & 8 & 3 & 24 & 22 \\
\hline
\end{tabular}

Источник: Федеральная служба государственной статистики, gks.ru [13]. 
Таблица 3. Уровень инновационной активности организаций - всего в 2017 году, \% [12]

\begin{tabular}{|c|c|c|c|}
\hline & $\begin{array}{c}\text { Удельный вес } \\
\text { организаций, } \\
\text { осуществлявших } \\
\text { инновационную } \\
\text { деятельность } \\
\text { в общем числе } \\
\text { обследованных } \\
\text { организаций, \% }\end{array}$ & $\begin{array}{c}\text { Удельный вес } \\
\text { организаций, } \\
\text { осуществлявших } \\
\text { технологиче- } \\
\text { ские инновации } \\
\text { в общем числе } \\
\text { обследованных } \\
\text { организаций, \% }\end{array}$ & $\begin{array}{c}\text { Удельный вес } \\
\text { организаций, осу- } \\
\text { ществлявших про- } \\
\text { цессные иннова- } \\
\text { ции в общем числе } \\
\text { обследованных } \\
\text { организаций, \% }\end{array}$ \\
\hline Всего по формам собственности & 8,5 & 7,5 & 4,4 \\
\hline Российская собственность & 8,3 & 7,4 & 4,3 \\
\hline Государственная собственность & 9,7 & 8,8 & 5,5 \\
\hline Федеральная собственность & 13,3 & 12,4 & 7,6 \\
\hline Собственность субъектов РФ & 4,9 & 3,9 & 2,8 \\
\hline Муниципальная собственность & 2,5 & 2,1 & 1,5 \\
\hline Частная собственность & 9,1 & 7,9 & 4,2 \\
\hline Собственность потребительской кооперации & 4,2 & 1,4 & 1,4 \\
\hline $\begin{array}{l}\text { Собственность общественных и религиозных } \\
\text { организаций (объединений) }\end{array}$ & 4,0 & 3,7 & 2,3 \\
\hline Собственность профессиональных союзов & 13,3 & 13,3 & - \\
\hline Собственность общественных объединений & 3,5 & 3,2 & 2,3 \\
\hline Собственность религиозных объединений & 9,1 & 9,1 & 9,1 \\
\hline Смешанная российская собственность & 17,7 & 16,6 & 10,9 \\
\hline Иностранная собственность & 6,9 & 6,0 & 3,4 \\
\hline Собственность иностранных юридических лиц & 7,0 & 6,1 & 3,5 \\
\hline $\begin{array}{l}\text { Собственность иностранных граждан и лиц без } \\
\text { гражданства }\end{array}$ & 4,8 & 4,8 & 2,4 \\
\hline Смешанная иностранная собственность & 4,9 & 4,9 & 3,7 \\
\hline $\begin{array}{l}\text { Совместная Российская и иностранная соб- } \\
\text { ственность }\end{array}$ & 14,1 & 12,3 & 7,8 \\
\hline $\begin{array}{l}\text { Совместная федеральная и иностранная соб- } \\
\text { ственность }\end{array}$ & 26,6 & 25,2 & 20,1 \\
\hline $\begin{array}{l}\text { Совместная собственность субъектов РФ и ино- } \\
\text { странная собственность }\end{array}$ & 20,0 & 16,7 & 13,3 \\
\hline $\begin{array}{l}\text { Совместная частная и иностранная собствен- } \\
\text { ность }\end{array}$ & 13,1 & 11,3 & 6,8 \\
\hline $\begin{array}{l}\text { Смешанная Российская собственность с долей } \\
\text { государственной собственности }\end{array}$ & 19,3 & 18,0 & 12,4 \\
\hline $\begin{array}{l}\text { Смешанная российская собственность с долей } \\
\text { федеральной собственности }\end{array}$ & 24,2 & 22,7 & 16,1 \\
\hline $\begin{array}{l}\text { Смешанная российская собственность с долей } \\
\text { собственности субъектов РФ }\end{array}$ & 8,6 & 7,8 & 4,6 \\
\hline $\begin{array}{l}\text { Смешанная российская собственность с долями } \\
\text { федеральной собственности и собственности } \\
\text { субъектов РФ }\end{array}$ & 20,0 & 17,3 & 10,7 \\
\hline Иная смешанная российская собственность & 14,1 & 13,4 & 7,3 \\
\hline Собственность государственных корпораций & 32,2 & 30,2 & 16,0 \\
\hline
\end{tabular}


Госсектор всегда выступал в качестве спасательного круга «тонущей» национальной экономики. Его позитивная роль сильно возрастала в периоды войны, подготовки к войне и кризисов. В ряде случаев госсектор наращивает свое значение при осуществлении страной экономического «прорыва» при освоении новых территорий и технологий.

В условиях нарастания санкций против России, невозможности получения дешевых кредитов и новых технологий, агрессивной русофобии по множественным направлениям и информационной войны проведение новой индустриализации без государственной собственности является невозможным.
Поэтому на нынешнем этапе развития приватизация должна быть приостановлена или она должна перейти на качественно новый уровень и проводиться на основе иных принципов и подходов. Также должна формироваться эффективная система управления государственным сектором.

Таким образом, проводимая политика российского правительства на приватизацию государственной собственности «до основания» в настоящее время является необоснованной, несостоятельной. Без государственных эффективных предприятий не удается осуществлять масштабные научно-технические программы и сглаживать региональные проблемы развития.

\section{Библиографический список}

1. Постановление Правительства РФ от 9 сентября 1999 г., Ф3 № 1024 «О Концепции управления государственным имуществом и приватизации в Российской Федерации» [Электронный ресурс]: (в ред. от 29.11.2000). http://docs.cntd.ru/document/1000000695/ [Дата обращения:14.06.2019].

2. Постановление Правительства РФ от 15 апреля 2014 г. № 327 «Государственная программа Российской Федерации «Управление федеральным имуществом» [Электронный ресурс]:. Доступ из справ.- правовой системы «КонсультантПлюс». http://ivo.garant.ru/\#/document/70644258/paragraph/1:1 [Дата обращения: 20.06.2019].

3. Постановление Правительства РФ от 31 марта 2017 г. № 381-12 «О внесении изменений в государственную программу Российской Федерации «Управление федеральным имуществом». https://www.garant.ru/ products/ipo/prime/doc/71550678/ [Дата обращения:10.05.2019].

4. Постановление Правительства РФ от 30 марта 2018 г. № 367-14 «О внесении изменений в государственную программу Российской Федерации «Управление федеральным имуществом». http://www.consultant.ru/ document/cons_doc_LAW_295168/ [Дата обращения:10.04.2019].

5. Распоряжение Правительства РФ от 8 декабря 2011 года N2227-р. «Стратегия инновационного развития Российской Федерации на период до 2020 года». http://www.consultant.ru/document/cons_doc_LAW_123444/ 2f806c88991ebbad43cdaa1c63c 2501dc94c14af/ [Дата обращения:11.05.2019].

6. Индикаторы инновационной деятельности: 2018: статистический сборник / Н.В. Городникова, Л.М. Гохберг, К.А. Дитковский и др.; Нац. исслед. ун-т И60 «Высшая школа экономики».- М.: НИУ ВШЭ, 2018, с. 78

7. Звягинцев П.С. Роль государственных программ в модернизации, инновационном и технологическом развитии и импортозамещении российской экономики. «Россия: тенденции и перспективы развития».- М.: ИНИОН РАН, 2017. Выпуск 12. Ч. 2.- 591-596 с.

8. Звягинцев П.С. Роль государственной собственности в инновационном развитии экономики страны. // Менеджмент и бизнес-администрирование. 2019. № 2. С. 33-47. опубликована в ж. МБА

9. Ликвидация ГУПов и МУПов откладывается? https:/www.pnp.ru/social/ likvidaciya-gupov-i-mupovotkladyvaetsya.html [Дата обращения:19.06.2019].

10. Россия в цифрах. 2018: Крат. стат. сб/ Росстат- М.:, 2018. С. 65.

11. Россия в цифрах. 2018: Крат. стат. сб/ Росстат- М.:, 2018. С. 208.

12. Статистика науки и образования. Выпуск 4. Инновационная деятельность в Российской Федерации. Инф.стат. мат.- М.: ФГБНУ НИИ РИНКЦЭ, 2018.с. 32.

13. Федеральная служба государственной статистики, gks.ru. [Дата обращения:11.07.2019].

14. Эффективное управление государственной собственностью в 2018-2024 гг. и до 2035 г. // Аналитический доклад / ЦСР. - 2018. С. 54.

15. https://zen.yandex.ru/media/etc/siluanov-esli-pravitelstvo-ne-budet-vkladyvat-svobodnye-dengi-v-ssha-torossiiane-ih-proediat-5ba469dec071d300ab51bc88. [Дата обращения:12.06.2019]. 